\title{
Characteristics of Cardioembolic Stroke Patient in Neurologic Ward Dr. Hasan Sadikin General Hospital Bandung
}

\author{
Adriana Damayanti, Lisda Amalia**, Reza W Sudjud ${ }^{* * * *}$ \\ * Faculty of Medicine Padjadjaran University- Hasan Sadikin Hospital \\ ** Department of Neurology Faculty of Medicine \\ Padjadjaran University-Hasan Sadikin Hospital \\ ${ }^{* * *}$ Department of Anesthesiology and Intensive Care Faculty of Medicine \\ Padjadjaran University-Hasan Sadikin Hospital \\ Jl. Pasteur 38, Bandung 40161, Indonesia \\ Email: adrianamarpaung@gmail.com
}

\begin{abstract}
Stroke is the second most common cause of death worldwide after heart disease. About $80 \%$ stroke cases are ischemic stroke. One of 4 people with ischemic stroke had cardioembolic stroke. Ninety percent of cardiac emboli obstruct cerebral blood vessels and caused neurological deficit. Cardioembolic stroke may be due to abnormalities in cardiac walls, rhythm, valve, or function. Stroke patients with cardiac abnormalities have poor prognosis. This retrospective descriptive study was done in May-June 2017. We collected 103 medical records of stroke patients from Department of Neurology, Dr. Hasan Sadikin General Hospital during January 2015- March 2016. Data regarding sex, age, education level, economic status, and cardiac abnormalities were recorded. Majority of subjects were female (53.4\%). The most frequent age group was 45-65 years old (49.51\%). Most subjects had low educational level (76.7\%) and low economic status (77.67\%). Among subjects, $41.75 \%$ had cardiac rhythm abnormalities, $29.13 \%$ had cardiac wall abnormalities, $14.56 \%$ had cardiac valve abnormalities, and $14.56 \%$ had cardiac function abnormalities. The most common cause of cardioembolic stroke was atrial fibrillation.
\end{abstract}

Keywords: cardioembolic stroke epidemiology, patient characteristics, cardiac disease 


\title{
Karakteristik Pasien Stroke Kardioemboli di Bangsal Neurologi RSUP Dr. Hasan Sadikin Bandung
}

\author{
Adriana Damayanti, Lisda Amalia**, Reza W Sudjud ${ }^{* * *}$ \\ * Fakultas Kedokteran Universitas Padjadjaran / RSUP. Dr. Hasan Sadikin Bandung \\ ** Departmen Neurologi Fakultas Kedokteran, \\ Universitas Padjadjaran/RSUP Dr. Hasan Sadikin, Bandung \\ ***:Departmen Anestesi dan Terapi Intensif Fakultas Kedokteran, \\ Universitas Padjadjaran/RSUP Dr. Hasan Sadikin, Bandung \\ Jl. Pasteur 38, Bandung 40161,Indonesia \\ Email: adrianamarpaung@gmail.com
}

\begin{abstract}
Abstrak
Stroke merupakan penyebab kematian nomor dua di dunia setelah penyakit jantung. Stroke infark menduduki $80 \%$ jenis stroke saat ini. Satu dari empat kasus stroke infark adalah stroke kardioemboli dimana hampir $90 \%$ emboli yang berasal dari jantung berakhir diotak sehingga defisit neurologi. Kelainan jantung yang bisa menyebabkan stroke kardioemboli antara lain kelainan dinding, irama, katup, dan fungsi jantung. Pasien dengan kelainan jantung dan stroke akan memiliki prognosis lebih buruk dibandingkan pasien stroke tanpa kelainan jantung dan juga sebaliknya. Penelitian menggunakan studi desain deskriptif retrospektif yang dilakukan dari Mei-Juni 2017 menggunakan teknik pengambilan total sampling. Sampel diambil dari 103 rekam medis pasien stroke Departemen Neurologi RSUP Dr. Hasan Sadikin Bandung dari Januari 2015-Maret 2016. Data dilaporkan berdasarkan jenis kelamin, usia, tingkat pendidikan, tingkat ekonomi, dan jenis kelainan jantung. Pasien mayoritas adalah perempuan $(53,4 \%)$. Kelompok usia terbanyak adalah $45-65$ tahun $(49,51 \%)$, dengan tingkat pendidikannya rendah $(76,7 \%)$, tingkat ekonominya rendah $(77,67 \%)$, serta kelainan jantung ada kelainan irama $(41,75 \%)$, dinding $(29,13 \%)$, katup $(14,56 \%)$, dan fungsi $(14,56 \%)$. Jenis kelainan jantung terbanyak adalah kelainan irama berupa fibrilasi atrial.
\end{abstract}

Kata Kunci: epidemiologi stroke kardioemboli, karakteristik pasien, kelainan jantung 


\section{Research Article}

\section{Pendahuluan}

Stroke merupakan kumpulan gejala klinis yang berkembang secara cepat sebagai adanya tanda gangguan fungsi otak secara keseluruhan (global) atau hanya di titik tertentu saja (fokal), dimana gejala klinis tersebut berlangsung selama 24 jam atau lebih atau menuju ke arah kematian yang disebabkan karena adanya gangguan pada pembuluh darah. ${ }^{1,2}$ Stroke merupakan penyebab kematian nomor dua di dunia setelah penyakit jantung. Pada tahun 2010, prevalensi stroke di dunia adalah 33 juta dengan insidensi 16.9 juta masyarakat. ${ }^{3}$ Jumlah penderita penyakit stroke di Indonesia tahun 2013 berdasarkan diagnosis tenaga kesehatan (nakes) diperkirakan sebanyak 1.236.825 orang, sedangkan berdasarkan diagnosis nakes dan gejala sebanyak 2.137.941 orang. Berdasarkan diagnosis nakes maupun diagnosis/gejala, propinsi Jawa Barat memiliki jumlah penderita terbanyak yaitu sebanyak 238.001 orang. ${ }^{4}$ Dalam laporan terakhir dari Departemen Kesehatan Indonesia, stroke dinyatakan sebagai penyebab kematian nomor satu di rumah sakit pemerintah terutama rumah sakit tipe A seperti Rumah Sakit Umum Pusat (RSUP) Dr. Hasan Sadikin Bandung. Di RSUP Dr. Hasan Sadikin Bandung, lebih dari 500 orang per tahun dirawat karena stroke. ${ }^{5}$

Secara patomekanisme, $20 \%$ pasien stroke merupakan pasien stroke perdarahan dan $80 \%$ merupakan pasien stroke iskemik/infark. ${ }^{6}$ Subtipe stroke infark tersebut adalah stroke kardioemboli yang disebabkan oleh emboli karena kelainan pada jantung. Hampir 90\% emboli jantung berakhir di otak sehingga defisit, dengan kriteria diagnosis dan pemeriksaan penunjang yang beragam mendapatkan angka stroke kardioemboli antara $15-20 \%$ dari seluruh stroke iskemik. $^{7}$ Satu dari empat kasus stroke iskemik adalah stroke yang berasal dari kardioemboli. Insidensi dari penyakit stroke kardioemboli pada populasi bisa mencapai 30 kasus dari 100.000 penduduk setiap tahunnya. Kelainan jantung yang bisa menyebabkan stroke kardioemboli antara lain kelainan dinding, irama, katup, dan fungsi. Pasien dengan stroke dan kelainan jantung akan memiliki prognosis lebih buruk dibandingkan pasien stroke tanpa kelainan jantung dan juga sebaliknya. ${ }^{3}$ Pasien tersebut juga memiliki kualitas hidup yang buruk serta bisa menyebabkan komplikasi yang menyebabkan kematian. ${ }^{2}$

\section{Metode}

Penelitian ini dilakukan dari bulan Mei-Juni 2017 di Bangsal Neurologi Rumah Sakit Umum Pusat Dr. Hasan Sadikin Bandung, menggunakan studi desain deskriptif retrospektif. Subjek penelitian ini adalah data rekam medik pasien stroke kardioemboli di Bangsal Neurologi RSUP Dr. Hasan Sadikin Bandung yang dirawat dalam rentang waktu Januari 2015-Maret 2016 dengan kriteria inklusi pasien yang diagnosis stroke kardioemboli, disertai dan dicantumkan 


\section{Research Article}

pemeriksaan foto toraks, pemeriksaan elektrokardiogram (EKG), CT scan, dan echocardiography, dimana salah satu dari keempat hasil pemeriksaan tersebut hasilnya tidak normal. Penelitian ini menggunakan metode total sampling. Pengambilan data penelitian telah mendapat ijin etik dari Komite Etik Rumah Sakit Dr. Hasan Sadikin Bandung dengan nomor 2187/DIKLIT/VI/2017.

Variabel yang diteliti dalam penelitian ini adalah diagnosis stroke kardioemboli, hasil pemeriksaan EKG, echocardiography, foto toraks, CT scan, usia, jenis kelamin, tingkat pendidikan, tingkat ekonomi, dan kelainan jantung pasien. Data diolah menggunakan program Microsoft Excel 2010 dan disajikan dalam bentuk tabel yang menggambarkan variabel yang diteliti.

\section{Hasil}

Dalam kurun waktu 15 bulan dari Januari 2015-Maret 2016, pasien yang terdiagnosis stroke kardioemboli berjumlah 137. Sebanyak 103 data rekam medis dari pasien stroke kardioemboli masuk kriteria inklusi, sedangkan 34 data terekslusi karena hasil pemeriksaan yang tidak lengkap.

Tabel 1 menunjukkan profil pasien stroke kardioemboli yang dirawat di Bangsal Neurologi RSUP Dr. Hasan Sadikin Bandung pada Januari 2015-Maret 2016. Pengelompokkan profil tersebut berdasarkan usia, jenis kelamin, tingkat pendidikan, tingkat ekonomi, serta jenis kelainan jantung yang dimiliki pasien. Berdasarkan usia, didapatkan bahwa kelompok usia 4565 tahun merupakan kelompok paling rentan terkena stroke kardioemboli dengan persentase 49,51\%. Angka kejadian stroke kardioemboli lebih tinggi pada wanita dibanding pria dengan persentase $53,4 \%$. Berdasarkan tingkat pendidikan, pasien dengan tingkat pendidikan yang tergolong rendah lebih sering terjadi stroke kardioemboli dibandingkan dengan tingkat pendidikan lain dengan persentase $76,7 \%$. Berdasarkan pekerjaan, pasien dengan tingkat ekonomi yang rendah lebih sering terkena stroke kardioemboli dengan persentase $77,67 \%$. Untuk jenis kelainan jantung, kelainan irama merupakan penyebab tersering yang menyebabkan stroke kardioemboli dengan persentase $41,75 \%$ dibandingkan jenis kelainan jantung lainnya.

Tabel 2 menunjukkan gambaran kelainan jantung berdasarkan jenis kelamin dan usia, dimana kelainan jantung paling banyak adalah kelainan irama yaitu fibrilasi atrial $(41,75 \%)$. Sementara kelainan jantung paling sedikit terjadi adalah kelainan katup yaitu regurgitasi aorta $(1,94 \%)$. Fibrilasi atrial sendiri paling banyak terjadi pada wanita dengan usia lebih dari 65 tahun. 
Tabel 1 Profil Pasien Stroke Kardioemboli

\begin{tabular}{lcc}
\hline \multicolumn{1}{c}{ Profil } & $\mathbf{N}$ & N=103 \\
\hline Usia & & \\
$<45$ & 13 & 12,62 \\
$45-65$ & 51 & 49,51 \\
$>65$ & 39 & 37,86 \\
Jenis kelamin & & \\
Pria & 48 & 46,60 \\
Wanita & 55 & 53,40 \\
Pendidikan & & \\
Rendah & 79 & 76,70 \\
Sedang & 22 & 21,36 \\
Tinggi & 2 & 1,94 \\
Ekonomi & & \\
Rendah & 80 & 77,67 \\
Sedang & 23 & 22,33 \\
Tinggi & 0 & 0,00 \\
Jenis kelainan jantung & & \\
Kelainan dinding & 30 & 29,13 \\
Kelainan katup & 15 & 14,56 \\
Kelainan irama & 43 & 41,75 \\
Kelainan fungsi & 15 & 14,56 \\
\hline
\end{tabular}

Tabel 2 Gambaran kelainan jantung berdasarkan jenis kelamin dan usia

\begin{tabular}{|c|c|c|c|c|c|c|c|c|}
\hline \multirow{2}{*}{$\begin{array}{l}\text { Jenis Kelainan } \\
\text { Jantung }\end{array}$} & \multicolumn{2}{|c|}{$<45$} & \multicolumn{2}{|c|}{$45-65$} & \multicolumn{2}{|c|}{$>65$} & \multirow[b]{2}{*}{$\sum$} & \multirow[b]{2}{*}{$\%$} \\
\hline & Pria & Wanita & Pria & Wanita & Pria & Wanita & & \\
\hline \multicolumn{9}{|l|}{ Kelainan dinding } \\
\hline Miokard infark & 1 & 0 & 3 & 2 & 2 & 1 & 9 & 8,74 \\
\hline Kardiomegali & 1 & 2 & 9 & 5 & 1 & 3 & 21 & 20,39 \\
\hline \multicolumn{9}{|l|}{ Kelainan katup } \\
\hline Stenosis mitral & 0 & 1 & 0 & 2 & 2 & 3 & 8 & 7,77 \\
\hline Regurgitasi mitral & 1 & 0 & 1 & 1 & 2 & 0 & 5 & 4,85 \\
\hline Regurgitasi aorta & 0 & 0 & 0 & 0 & 1 & 1 & 2 & 1,94 \\
\hline \multicolumn{9}{|l|}{ Kelainan irama } \\
\hline Fibrilasi atrial & 1 & 3 & 7 & 10 & 8 & 14 & 43 & 41,75 \\
\hline \multicolumn{9}{|l|}{ Kelainan fungsi } \\
\hline $\begin{array}{l}\text { Disfungsi } \\
\text { diastolik }\end{array}$ & 2 & 1 & 6 & 5 & 0 & 1 & 15 & 14,56 \\
\hline \multirow{2}{*}{ Jumlah } & 6 & 7 & 26 & 25 & 16 & 23 & 103 & \\
\hline & 5,83 & 6,80 & 25,24 & 24,27 & 15,53 & 22,33 & 100 & \\
\hline
\end{tabular}

\section{Diskusi}

Hasil penelitian menunjukkan bahwa pasien stroke kardioemboli yang dirawat di Bangsal Neurologi RSUP Dr. Hasan Sadikin Bandung sebagian besar adalah wanita. Hasil ini sesuai dengan penelitian Smith yang menyatakan pada usia produktif, insidensi wanita terkena stroke kardioemboli adalah $62 \%$ dibanding pria yaitu 38\%. Hal ini juga disebabkan karena fibrilasi atrial lebih sering terjadi pada wanita. ${ }^{8,9}$ Usia pasien stroke kardioemboli paling tinggi berada 


\section{Research Article}

pada kelompok usia 45-65 tahun, sesuai dengan penelitian Anderson dkk yang menyatakan bahwa pergeseran usia pasien stroke menjadi kelompok umur lebih muda disebabkan karena seiring berkembangnya jaman, gaya hidup masyarakat menjadi tidak sehat karena faktor nutrisi yang tidak seimbang serta kurangnya olahraga. ${ }^{10}$

Dilihat dari tingkat pendidikan, pasien terbanyak pada kelompok pendidikan rendah yaitu pasien maksimal lulus SMP atau bahkan tidak bersekolah. Hal ini sesuai dengan penelitian Ahacic dkk yang menyatakan bahwa mayoritas pasien stroke kardioemboli merupakan pasien dari kalangan pendidikan yang rendah, sehingga pasien tersebut memiliki keterbatasan pengetahuan terhadap tindakan untuk mencegah stroke terjadi. ${ }^{11}$ Dari segi tingkat ekonomi, pasien paling banyak dari tingkat ekonomi rendah, dimana menurut International Standard Classification of Occupation pekerjaan mayoritas pasien adalah tidak bekerja, ibu rumah tangga, petani, dan buruh. Hal ini sesuai dengan penelitian Ahacic yang menyatakan bahwa pasien stroke kardioemboli rata-rata berpenghasilan rendah. Mereka tidak melakukan pengobatan sehingga permasalahan pada jantung menyebabkan emboli semakin parah dan menyebabkan stroke. ${ }^{12}$

Untuk jenis kelainan jantung, kelainan paling sering adalah kelainan irama (41,75\%), kelainan dinding (29,13\%), kelainan katup (14,56\%), dan kelainan fungsi $(14,56 \%)$. Menurut Kamel, kelainan irama jantung hampir seluruhnya disebabkan karena fibrilasi atrial. Hasil penelitian ditemukan $41,75 \%$ pasien mengalami fibrilasi atrial karena trombus atau emboli terbentuk akibat kontraksi tidak teratur endokardium yang menyebabkan trombus terlepas menjadi emboli. ${ }^{11}$ Menurut Massimo dkk, jenis fibrilasi atrial tersering adalah fibrilasi atrial permanen $(50 \%)$, paroksismal $(30 \%)$, dan persisten $(20 \%) .{ }^{13}$ Untuk kelainan dinding, paling banyak disebabkan karena kardiomegali $(20,39 \%)$ diikuti dengan miokard infark $(8,74 \%)$. Menurut Yaghi, $81 \%$ pasien yang mengalami kelainan dinding jantung pada stroke kardioemboli disebabkan karena kardiomegali. Kondisi kardiomegali pada pasien stroke kardioemboli ini identik dengan bagian jantung berupa pembesaran atrium kiri. ${ }^{14}$

Kelainan jantung lainnya yaitu kelainan katup, paling banyak disebabkan oleh stenosis mitral (7,77\%), diikuti dengan regurgitasi mitral (4,85\%) dan regurgitasi aorta $(1,94 \%)$. Menurut Yaghi, mayoritas stroke kardioemboli terjadi karena stenosis mitral, dimana terjadi penyempitan lumen sampai selebar pensil, sehingga atrium kiri mengalami kesulitan dalam mengosongkan darah melalui lumen yang sempit ke ventrikel kiri. ${ }^{14}$ Kelainan fungsi jantung juga menyebabkan stroke kardioemboli yaitu disfungsi diastolik (14,56\%). Hal ini didukung oleh penelitian Rosenberg bahwa disfungsi diastolik akan meningkatkan risiko enam kali untuk terkena fibrilasi atrial yang nantinya bisa menyebabkan stroke kardioemboli. ${ }^{15}$ 


\section{Research Article}

Keterbatasan penelitian ini diantaranya jumlah subjek penelitian yang terbatas sehingga hasilnya belum dapat digeneralisasikan kelompok yang besar. Banyak kriteria eksklusi karena hasil pemeriksaan pasien tidak lengkap sehingga sampel hanya 103. Banyak pasien tidak melakukan pemeriksaan echocardiography karena pasien sudah terlebih dahulu meninggal atau karena faktor keadaan ekonomi sehingga tidak mampu untuk melakukan pemeriksaan echocardiography.

\section{Simpulan}

Dari penelitian ini dapat disimpulkan bahwa anggota pasien stroke kardioemboli yang dirawat di Bangsal Neurologi RSUP Dr. Hasan Sadikin Bandung periode Januari 2015-Maret 2016 paling banyak adalah perempuan, secara umum rentang usia 45-65 tahun, tingkat pendidikan rendah, tingkat ekonomi rendah, serta jenis kelainan jantung terbanyak adalah kelainan irama berupa fibrilasi atrial. Penelitian selanjutnya diharapkan dapat meneliti secara cohort untuk mencari faktor risiko pada pasien dengan gangguan jantung untuk mencegah terjadinya stroke kardioemboli.

\section{Daftar Pustaka}

1. Truelsen T, Begg S, Mathers C. The global burden of cerebrovascular disease. Geneva World Health Organization. 2000.

2. Persky RW, Turtzo LC, McCullough LD. Stroke in Women: Disparities and Outcomes. Current cardiology reports. 2010;12(1):6-13.

3. Benjamin EJ, Blaha MJ, et al. Heart Disease and Stroke Statistics-2017 Update: A Report From the American Heart Association. Circulation. 2017;135(10):e146-e603.

4. Badan Penelitian dan Pengembangan Kesehatan Kementerian Kesehatan RI. Riset kesehatan dasar 2013. Kementerian Kesehatan Republik Indonesia. Jakarta; 2013.

5. Rizal DA. Stroke dan hipertensi [diunduh 3 Oktober 2016]. Tersedia dari: http://web.rshs.or.id/823/

6. Fadjar E. Stroke pembunuh nomor 3 di dunia. Tempo. Jakarta; 2014 [diunduh 3 Oktober 2016]. Tersedia dari: http://gaya.tempo.co/read/news/2014/08/28/060602884/stroke-pembunuhnomor-3-di-dunia

7. Hauser S, Josephson S. Harrison's Neurology in Clinical Medicine. 3rd ed. San Fransisco: McGraw Hill Professional; 2013. 261-66.

8. Turtzo LC, McCullough LD. Sex Differences in Stroke. Cerebrovascular Disease. 2008; 26(5): 462-74.

9. Smith MA, Lisabeth LD, Brown DL, Morgenstern LB. Gender comparisons of diagnostic evaluation for ischemic stroke patients. American Heart Association Journals. 2007; 65(6): 855-8.

10. Sue V. Saxon, PhD, Mary Jean Etten, EdD. Physical change and aging, Sixth Edition: A guide for the helping professions. 6th ed. Springer Publishing Company; 2014. p.148.

11. Kamel H, Okin PM, Elkind MS, Iadecola C. Atrial fibrillation and mechanisms of stroke. Stroke. 2016; 47(3): 895-900.

12. Ahacic K, Kåreholt I. Income and education as predictors of return to working life among younger stroke patients. BMC Public Health. 2011 Sep;11(1):742.

13. Zoni-Berisso M, Lercari F, Carazza T, Domenicucci S. Epidemiology of atrial fibrillation: European perspective. Clin Epidemiol. New Zealand; 2014; 6(1): 213-20.

14. Yaghi S, Moon YP. Left atrial enlargement and stroke recurrence: the Northern Manhattan Stroke Study. Stroke. 2015; 46(6): 1488-93.

15. Rosenberg MA, Manning WJ. Diastolic dysfunction and risk of atrial fibrillation: a mechanistic appraisal. Circulation. 2012; 126(19):2353-62. 